\title{
Vitamin C Crosses the Blood-Brain Barrier in the Oxidized Form Through the Glucose Transporters
}

\author{
David B. Agus, ${ }^{\star}$ Sanjiv Sam Gambhir, ${ }^{\ddagger}$ William M. Pardridge, ${ }^{\S}$ Charles Spielholz, ${ }^{\star}$ José Baselga, ${ }^{\|}$Juan Carlos Vera, ${ }^{\star}$ \\ and David W. Golde* \\ *Memorial Sloan-Kettering Cancer Center, New York, New York 10021; ${ }^{\ddagger}$ Crump Institute for Biological Imaging, Department of \\ Molecular \& Medical Pharmacology; ${ }^{\S}$ Department of Medicine, Brain Research Institute, UCLA School of Medicine, Los Angeles, \\ California 90095; and "Vall D'Hebron Hospital General, Barcelona 08035, Spain
}

\begin{abstract}
Vitamin C concentrations in the brain exceed those in blood by 10 -fold. In both tissues, the vitamin is present primarily in the reduced form, ascorbic acid. We identified the chemical form of vitamin $\mathrm{C}$ that readily crosses the blood-brain barrier, and the mechanism of this process. Ascorbic acid was not able to cross the blood-brain barrier in our studies. In contrast, the oxidized form of vitamin $\mathrm{C}$, dehydroascorbic acid (oxidized ascorbic acid), readily entered the brain and was retained in the brain tissue in the form of ascorbic acid. Transport of dehydroascorbic acid into the brain was inhibited by D-glucose, but not by L-glucose. The facilitative glucose transporter, GLUT1, is expressed on endothelial cells at the blood-brain barrier, and is responsible for glucose entry into the brain. This study provides evidence showing that GLUT1 also transports dehydroascorbic acid into the brain. The findings define the transport of dehydroascorbic acid by GLUT1 as a mechanism by which the brain acquires vitamin $C$, and point to the oxidation of ascorbic acid as a potentially important regulatory step in accumulation of the vitamin by the brain. These results have implications for increasing antioxidant potential in the central nervous system. (J. Clin. Invest. 1997. 100:28422848.) Key words: ascorbic acid - dehydroascorbic acid • GLUT1 • neurodegenerative disease • antioxidants
\end{abstract}

\section{Introduction}

A considerable body of information exists regarding the role of vitamin $\mathrm{C}$ in mammalian physiology. Humans and other primates cannot synthesize vitamin $\mathrm{C}$, whereas most mammals (e.g., rat and mouse) endogenously produce vitamin $\mathrm{C}$ in the liver (1). Vitamin $\mathrm{C}$ is absorbed from the gastrointestinal tract in the form of ascorbic acid, while dehydroascorbic acid is reduced to ascorbic acid for gastrointestinal absorption (2). Most ascorbic acid is excreted by the kidneys, but a limited amount is metabolized in the body. Ascorbic acid is oxidized to dehy-

Address correspondence to David B. Agus, M.D., Memorial SloanKettering Cancer Center, 1275 York Avenue, Box 560, New York, NY 10021. Phone: 212-639-2820; FAX: 212-772-8550; E-mail: d-agus@ ski.mskcc.org

Received for publication 25 August 1997 and accepted in revised form 16 October 1997.

J. Clin. Invest.

(C) The American Society for Clinical Investigation, Inc. 0021-9738/97/12/2842/07 \$2.00

Volume 100, Number 11, December 1997, 2842-2848

http://www.jci.org droascorbic acid, which can undergo irreversible hydrolysis to 2,3-diketo-L-gulonic acid, with decarboxylation to $\mathrm{CO}_{2}$ and components of the pentose phosphate cycle or oxalic acid plus threonic acid.

Vitamin $\mathrm{C}$ is required for vascular and connective tissue integrity as well as normal hematopoiesis and leukocyte function (3-8). The vitamin is believed to have critical functions in the brain, including a role as a cofactor of dopamine $\beta$-hydroxylase, and is thus involved in catecholamine biosynthesis. Vitamin $\mathrm{C}$ also inhibits peroxidation of membrane phospholipids, and acts as a scavenger of free radicals in the brain $(7,8)$. Vitamin $\mathrm{C}$ is present in the brain tissue at high concentrations compared to other organs (9), and there is a greater than 10-fold gradient between the concentration of ascorbic acid in brain and serum, leading investigators to postulate a regulatable, active transport mechanism for ascorbic acid into the brain $(4,9$, 10). Evidence for such a transport mechanism arose from the observed lack of an immediate increase in the cerebrospinal fluid and brain concentration of ascorbic acid after intravenous injection of ascorbic acid in rodents (4).

Ehrlich found that intravenously injected aniline dyes colored all of the organs of experimental rabbits except the brain and the spinal cord $(11,12)$. This observation led to the eventual discovery that the blood-brain barrier is comprised of a wall of capillaries forming an endothelial barrier between the blood and the brain, functioning primarily to regulate the transport of nutrients and waste products $(13,14)$. Several nutrient transporters have been identified at the blood-brain barrier, including the facilitative glucose transporter (GLUT1), ${ }^{1}$ a monocarboxylic acid transporter, a neutral amino acid transporter, an amine transporter, a basic amino acid transporter, a nucleoside transporter, and a purine base transporter (15).

We previously found that dehydroascorbic acid (oxidized ascorbic acid), the oxidized form of vitamin C, is transported through facilitative glucose transporters (16). Expression of mammalian glucose transporters in Xenopus oocytes conferred the ability to take up dehydroascorbic acid, which was retained intracellularly after it was reduced to ascorbic acid (16). We also established that facilitative glucose transporters are involved in the transport and accumulation of vitamin $\mathrm{C}$ by normal human neutrophils and the myeloid leukemia cell line, HL-60 (16-18). In these cells, dehydroascorbic acid is transported across the cell membrane and accumulated in the reduced form, ascorbic acid, which is not transportable through the bidirectional glucose transporters (16-18). Ascorbic acid may also be transported through a $\mathrm{Na}^{+}$-ascorbate cotrans-

1. Abbreviations used in this paper: AA, ascorbic acid; DHA, dehydroascorbic acid; dpm, decays per minute; GLUT1, facilitative glucose transporter. 
porter that is reported to be present in the small intestine, renal epithelial cells, osteoblasts, adrenomedullary chromaffin cells, and fibroblasts (19-25). Sodium-sensitive uptake of ascorbic acid was also demonstrated by expression studies in Xenopus oocytes injected with poly $(\mathrm{A})^{+}$RNA extracted from rabbit kidney cortex (26). The cotransporter has not been molecularly characterized, and we have found no $\mathrm{Na}^{+}$-dependent ascorbic acid uptake in white blood cells $(17,18)$.

In this study, we found that vitamin $\mathrm{C}$ crosses the bloodbrain barrier in the oxidized form, dehydroascorbic acid. The dehydroascorbic acid traverses the blood-brain barrier through GLUT1, and it is subsequently reduced and retained in the brain in the reduced form, ascorbic acid. Since only ascorbic acid is detected in the serum, with dehydroascorbic acid at trace or unmeasurable serum levels (27), oxidation of ascorbic acid may be an important step regulating brain uptake of vita$\min \mathrm{C}$.

\section{Methods}

Blood-brain barrier in vivo transport studies. Balb/c mice (ages 6-8 wk) and Fischer F344 rats (70-80 grams body weight) were injected into the tail vein with $5 \mu \mathrm{Ci}$ in the mouse (a dose expected to lead to an in vivo concentration of $\sim 250 \mu \mathrm{M}$, based on the average blood volume of the mouse) or $10 \mu \mathrm{Ci}$ in the rat of $\left[{ }^{14} \mathrm{C}\right]$ ascorbic acid (L-[1${ }^{14} \mathrm{C}$ ]ascorbic acid, specific activity, $6.6 \mathrm{mCi} / \mathrm{mmol}$; DuPont-NEN, Boston, MA), $\left[{ }^{14} \mathrm{C}\right]$ dehydroascorbic acid, or $\left[{ }^{3} \mathrm{H}\right]$ sucrose ([fructose$\left.1-{ }^{3} \mathrm{H}\right]$ sucrose, specific activity $20.0 \mathrm{Ci} / \mathrm{mmol}$; Dupont NEN). $\left[{ }^{14} \mathrm{C}\right]$ Dehydroascorbic acid was generated in all experiments by incubating $\left[{ }^{14} \mathrm{C}\right]$ ascorbic acid with ascorbate oxidase, $1 \mathrm{U} / 1.0 \mathrm{mmol} \mathrm{L}$-ascorbate (derived from Cucurbita species; Sigma Chemical Co., St. Louis, MO). Dithiothreitol $(0.1 \mathrm{mmol} /$ liter $)$ was added to the vitamin $\mathrm{C}$ preparations (both ascorbic acid and dehydroascorbic acid). Animals were killed at various time points after intravenous injection by cervical dislocation or $\mathrm{CO}_{2}$ inhalation. The brain was dissected and homogenized in $70 \%$ methanol, and the serum fraction of blood was placed in $70 \%$ methanol. Samples were processed for scintillation spectrometry or HPLC as described $(17,18)$. HPLC was performed on the methanol fraction with $1 \mathrm{mmol} /$ liter EDTA added $(17,18)$. Samples were stored at $-70^{\circ} \mathrm{C}$ until analysis. HPLC samples were separated on a strong anion exchange Partisil $10 \mathrm{SAX}(4.6 \times 25 \mathrm{~cm})$ column (Whatman Inc., Clifton, NJ). A Whatman-type WCS solventconditioning column was used, and the eluates were monitored with a System Gold liquid chromatograph (Beckman Instruments, Inc., Fullerton, CA) with a diode array detector and radioisotope detector arranged in series. Ascorbic acid was monitored by absorbance at 265 $\mathrm{nm}$, and by radioactivity. Dehydroascorbic acid has no absorbance at $265 \mathrm{~nm}$, and was monitored by radioactivity.

Calculation of the blood-brain barrier permeability-surface area product. The amount of compound crossing the blood-brain barrier is dependent on two parameters defined by the following equation: \% injected dose/g of brain tissue $=$ PS $\times \mathrm{AUC}_{0}^{t}$ where PS is the bloodbrain barrier permeability-surface area product, and $\left.\mathrm{AUC}\right|_{0} ^{t}$ is the plasma area under the concentration time-activity curve at a given time (t) after injection. A variant of the single intravenous injection technique, termed the external organ technique, was used to quantify the blood-brain barrier-PS product in anesthetized animals. The plasma and brain radioactivities were measured as decays per minute $(\mathrm{dpm}) / \mu \mathrm{l}$ of serum (after the ascorbic acid or sucrose was solubilized from the cells in the presence of $70 \%$ methanol) which was equivalent to the integral of the plasma radioactivity. The blood-brain barrier PS product is calculated as follows:

Blood-brain barrier $-\mathrm{PS}=\frac{\mathrm{V}_{\mathrm{D}}-\mathrm{V}_{0}}{t}$
The variables are defined as follows:

$$
\begin{aligned}
& t=\text { time } \\
& \mathrm{V}_{\mathrm{D}}= \\
& \frac{\left[\left[{ }^{14} \mathrm{C}\right] \text { ascorbic acid (AA) or dehydroascorbic acid (DHA) }\right] \mathrm{dpm}}{\mathrm{g} \text { brain tissue }} \\
& \frac{\left[\left[{ }^{14} \mathrm{C}\right] \mathrm{AA} \text { or DHA }\right] \mathrm{dpm}}{\mu 1 \text { serum }} \text { (external organ) } \\
& \mathrm{V}_{0}=\frac{\frac{\left[\left[{ }^{3} \mathrm{H}\right] \text { sucrose }\right] \mathrm{dpm}}{\mathrm{g} \text { brain tissue }} \text { (brain) }}{\frac{\left[\left[{ }^{3} \mathrm{H}\right] \text { sucrose }\right] \text { dpm }}{\mu 1 \text { serum }} \text { (external organ). }}
\end{aligned}
$$

The rats were anesthetized with a mixture of ketamine $(90 \mathrm{mg} / \mathrm{kg})$ and xylazine $(10 \mathrm{mg} / \mathrm{kg})$ during the procedure. Xylazine caused hyperglycemia and hypoinsulinemia in the animals with a serum glucose of $\sim 280 \mathrm{mg} / \mathrm{dl} 30 \mathrm{~min}$ after anesthesia induction $(28,29)$. The serum glucose in these experiments was threefold higher than baseline glucose concentrations in the rats, and competed for transport through GLUT1, affecting PS calculations. Only the experiments done to calculate the blood-brain barrier permeability-surface area product involved anesthesia. Radiolabeled test compound $\left(\left[{ }^{3} \mathrm{H}\right]\right.$ sucrose, $\left[{ }^{14} \mathrm{C}\right]$ ascorbic acid, or $\left[{ }^{14} \mathrm{C}\right]$ dehydroascorbic acid) was injected into a cannulated femoral vein in several groups with three rats each. Sucrose was used as a $\mathrm{V}_{0}$ marker (plasma volume marker). For $30 \mathrm{~s}(\mathrm{t})$ after injection, arterial blood was collected by gravity from a catheter cannulated in the abdominal aorta, the animal was killed, and the brain was harvested and processed as described above.

Digital autoradiography. Animals were killed, frozen in a dry ice/ hexane mixture, and embedded in 5\% carboxymethylcellulose (Sigma Aldrich, St. Louis, MO). The animal blocks equilibrated for $\sim 12 \mathrm{~h}$ at $-20^{\circ} \mathrm{C}$, and the animals were sectioned in coronal cuts with a slice thickness of $\sim 40-45 \mu \mathrm{m}$ in a cryomicrotome (PMV) and tape-lifted for direct exposure onto digital plates (30). The exposure time was $\sim 72 \mathrm{~h}$. All digital plates were scanned on a Bas 5000 digital autoradiographic system (Fuji Photo Film Co., Tokyo, Japan) at a $25-\mu \mathrm{m}$ resolution.

\section{Results}

Blood-brain barrier transport of vitamin $C$. Mice and rats were injected into the tail vein with $\left[{ }^{14} \mathrm{C}\right]$ ascorbic acid, $\left[{ }^{14} \mathrm{C}\right]$ dehydroascorbic acid, or $\left[{ }^{3} \mathrm{H}\right]$ sucrose. 3 min after intravenous injection, the animals were killed, the brains were harvested, and the methanol-soluble fraction was counted by liquid scintillation. Approximately $4 \%$ of the dehydroascorbic acid (expressed as percent of injected dose [ID] per $g$ of brain tissue) was found in the brain after $3 \mathrm{~min}$ (Fig. 1, $A$ and $B$ ). Injected ascorbic acid and sucrose yielded only trace radioactivity in the brain homogenate at $3 \mathrm{~min}$, indicating that ascorbic acid could not pass the blood-brain barrier. Because sucrose is not metabolized or transported, it is used as a marker of plasma volume (31). The small amount of radioactivity present in the brain of the sucrose- and ascorbic acid-injected animals was consistent with the radioactivity present within the brain blood vessels. Control experiments were performed to demonstrate that the ascorbate oxidase used to generate dehydroascorbic acid did not affect the transport results. Ascorbate oxidase was injected into five mice $15 \mathrm{~s}$ after radiolabeled ascorbic acid was injected. Addition of ascorbate oxidase resulted in no change in radiolabeled ascorbic acid in the brain. We also performed experiments with dehydroascorbic acid generated by infusion of boron gas as the oxidant (data not shown). The results were 
A

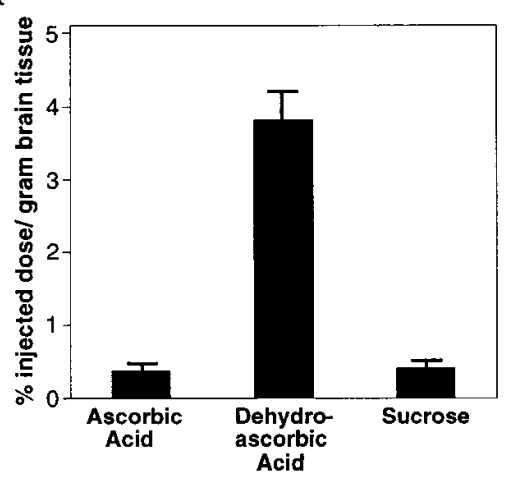

D

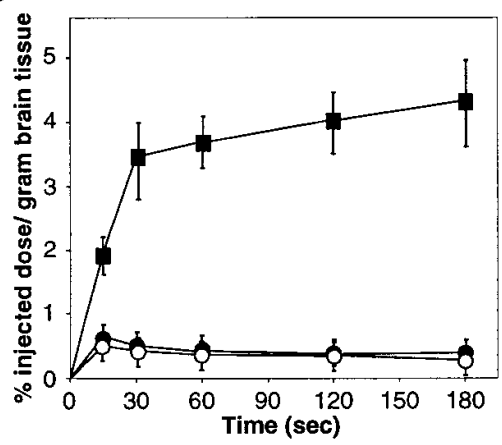

F

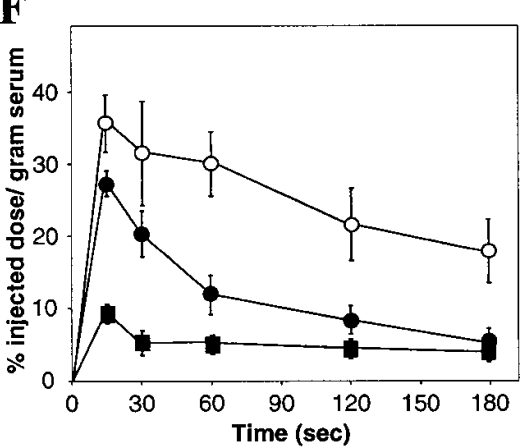

B

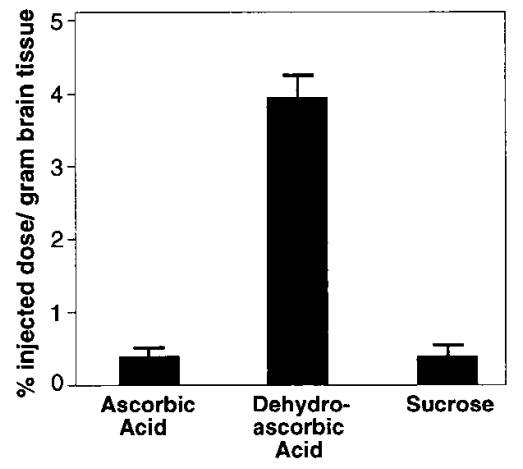

E

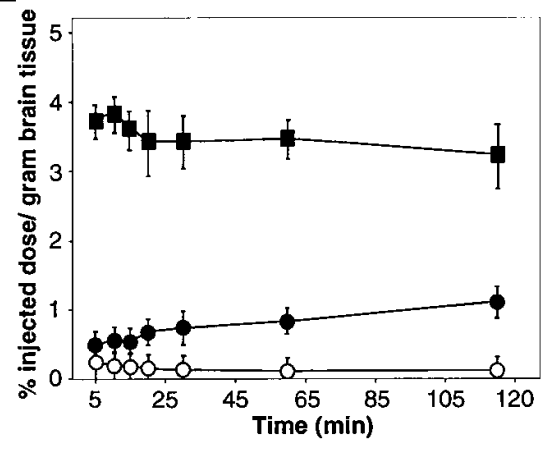

C

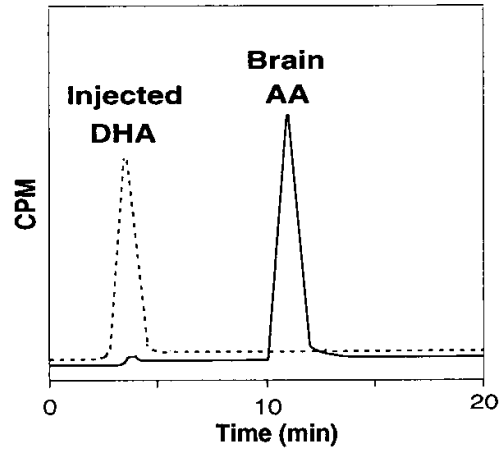

G

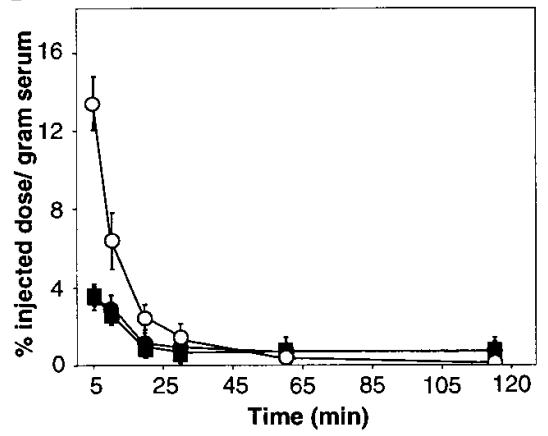

H

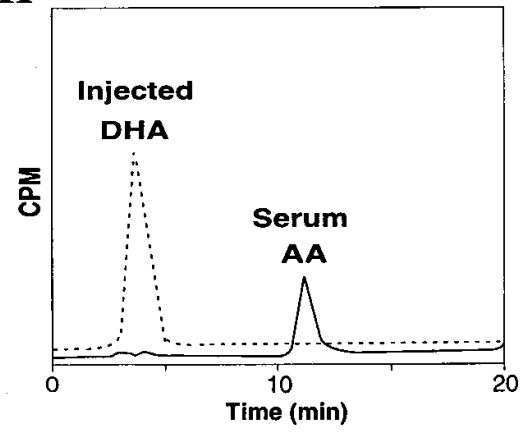

Figure 1. Dehydroascorbic acid is transported across the blood-brain barrier and accumulates in the brain as ascorbic acid. $(A)$ Mice and $(B)$ rats were injected into the tail vein with $\left[{ }^{14} \mathrm{C}\right]$ ascorbic acid, $\left[{ }^{14} \mathrm{C}\right]$ dehydroascorbic acid, or $\left[{ }^{3} \mathrm{H}\right]$ sucrose. Each group consisted of 12 animals, and values are expressed as mean \pm SEM. (C) HPLC analysis of the methanol-soluble fraction of the brain (solid line) of a mouse injected with $20 \mu \mathrm{Ci}$ $\left[{ }^{14} \mathrm{C}\right]$ dehydroascorbic acid (the HPLC result of the injected material is shown in the broken line) and killed at 5 min. $(C)$ Accumulation of vitamin $\mathrm{C}$ in the brain is in the form of ascorbic acid $(\sim 90 \%$; retention time, $\sim 11.80 \mathrm{~min}$, solid line $)$ in the dehydroascorbic acid-injected animal (the HPLC result of the injected material is shown in the broken line). (D) The initial kinetics and $(E)$ 2-h kinetics of accumulation of radioactivity in the brain of mice injected intravenously with $\left[{ }^{14} \mathrm{C}\right]$ ascorbic acid $(\bullet),\left[{ }^{14} \mathrm{C}\right]$ dehydroascorbic acid $(\boldsymbol{\square})$, or $\left[{ }^{3} \mathrm{H}\right]$ sucrose $(O)$. $(F)$ The initial kinetics and $(G)$ 2-h kinetics of radioactivity in the serum of mice injected intravenously with $\left[{ }^{14} \mathrm{C}\right]$ ascorbic acid $(\bullet),\left[{ }^{14} \mathrm{C}\right]$ dehydroascorbic acid $(\boldsymbol{\square})$, or $\left[{ }^{3} \mathrm{H}\right]$ sucrose $(\bigcirc)$. (H) HPLC analysis of the methanol-soluble fraction of serum (solid line) of a mouse injected with $20 \mu \mathrm{Ci}\left[{ }^{14} \mathrm{C}\right] \mathrm{dehy}-$ droascorbic acid (the HPLC result of the injected material is shown in the broken line) and killed at 5 min. Radioactivity present in serum is in the form of ascorbic acid ( $>98 \%$; retention time, $\sim 11.80 \mathrm{~min}$, solid line) in the dehydroascorbic acid-injected animal (the HPLC result of the injected material is shown in the broken line). Each data set in $D-H$ represents four mice \pm SEM.

equivalent to those obtained using ascorbate oxidase as the oxidant. HPLC analysis of the methanol fraction of the brain homogenate revealed that the form of vitamin $\mathrm{C}$ accumulated in the brains of dehydroascorbic acid-injected animals was $>85 \%$ ascorbic acid (Fig. $1 C$ ). These results indicate that dehydroascorbic acid was transported across the blood-brain barrier and retained as ascorbic acid in the brain.
Time kinetics of vitamin C transport in vivo. Brain radioactivity after dehydroascorbic acid injection, reached a maximum of $4.3 \%$ of ID/g brain tissue at $3 \mathrm{~min}$, decreased to $3.3 \%$ at $25 \mathrm{~min}$, and remained at that level for up to $2 \mathrm{~h}$ after injection (Fig. 1, $D$ and $E$ ). Injection of sucrose and ascorbic acid resulted in a maximum brain accumulation of $0.4 \% \mathrm{ID} / \mathrm{g}$ brain tissue 15 to $30 \mathrm{~s}$ after injection (Fig. $1 \mathrm{D}$ ). Brain radioactivity in 
the sucrose-injected animals decreased to $<0.1 \%$ after $15 \mathrm{~min}$, concomitant with the fall in serum radioactivity in these mice (Fig. 1, $E$ and $G$ ). In ascorbic acid-injected mice there was an increase in brain radioactivity to $1.1 \%$ ID/g brain tissue $2 \mathrm{~h}$ after injection, a time period during which there was a decreasing amount of radioactivity in the serum (Fig. $1, E$ and $G$ ). The serum radioactivity concentration $15 \mathrm{~s}$ after dehydroascorbic acid injection was $8 \% \mathrm{ID} / \mathrm{g}$ serum, whereas the corresponding figure in mice injected with ascorbic acid was $27 \%$. Thus, dehydroascorbic acid was cleared from the circulation substantially faster than ascorbic acid (Fig. $1 F$ ). At the 3-min time point the radioactivity in the serum of the ascorbic acid-and dehydroascorbic acid-injected animals was equivalent (Fig. $1 G$ ). Radioactivity remaining in the serum of the dehydroascorbic acid-injected animals at 5 min was associated with ascorbic acid (Fig. $1 H$ ).

The serum concentration of injected dehydroascorbic acid reached only $20-25 \%$ of the serum concentration of ascorbic acid or sucrose during the initial several minutes after injection (Fig. $1 F$ ). As sucrose has no transport mechanism, its clearance from the serum was slow. Cellular transport is a clearance mechanism for ascorbic acid and dehydroascorbic acid, with the participation of glucose transporters in the case of dehydroascorbic acid and possibly a $\mathrm{Na}^{+}$-ascorbate cotransporter in the case of ascorbic acid (19-25). The rapid clearance of dehydroascorbic acid from the serum likely reflected the large number of glucose transporters available.

Injected $\left[{ }^{14} \mathrm{C}\right]$ ascorbic acid showed no measurable transport into the brain over the first $30 \mathrm{~min}$, but some radioactivity accumulated in the brain at longer time periods. There are at least three potential explanations for this result. The first is that the ascorbic acid was metabolized in the serum in the interval time period, and the radioactivity in the brain represented transported radiolabeled metabolic breakdown products of ascorbic acid. Such an explanation is unlikely as the HPLC results demonstrated that the majority of the radioactivity in the brains of dehydroascorbic acid-injected animals was eluted in radioactive peaks consistent with intact ascorbic acid. A second possibility is the presence of some $\mathrm{Na}^{+}$-ascorbate cotransporters at the blood-brain barrier or choroid plexus (2). We do not consider this possibility likely since accumulation of ascorbic acid did not occur linearly with time, but only occurred after $30 \mathrm{~min}$. Nonetheless, our results do not rule out the notion that ascorbic acid in the blood may be directly transported into the brain. We favor the interpretation that oxidation of ascorbic acid in the microenvironment occurred in vivo, leading to the production of dehydroascorbic acid that was then transported across the blood-brain barrier and trapped in the brain as ascorbic acid.

Digital autoradiography of the rat brain. Digital autoradiography of the brain of a rat injected with $\left[{ }^{14} \mathrm{C}\right]$ dehydroascorbic acid and a rat injected with $\left[{ }^{14} \mathrm{C}\right]$ ascorbic acid was performed to confirm the anatomical distribution of the injected compounds (Fig. 2). Autoradiographic evidence of activity accumulation in the brain was seen only in animals injected with dehydroascorbic acid. $\left[{ }^{14} \mathrm{C}\right]$ sucrose was used as a marker of intravascular volume. The photostimulated luminescence (PSL)/ $\mathrm{mm}^{2}$ ratio of brain/background counts for the dehydroascorbic acid-injected rat was $8.6 \pm 0.3$ (mean of three sections \pm SEM). The $\mathrm{PSL} / \mathrm{mm}^{2}$ ratio in the ascorbic acid-injected rat was $1.5 \pm 0.1$ and $1.4 \pm 0.1$ in the sucrose-injected rat.
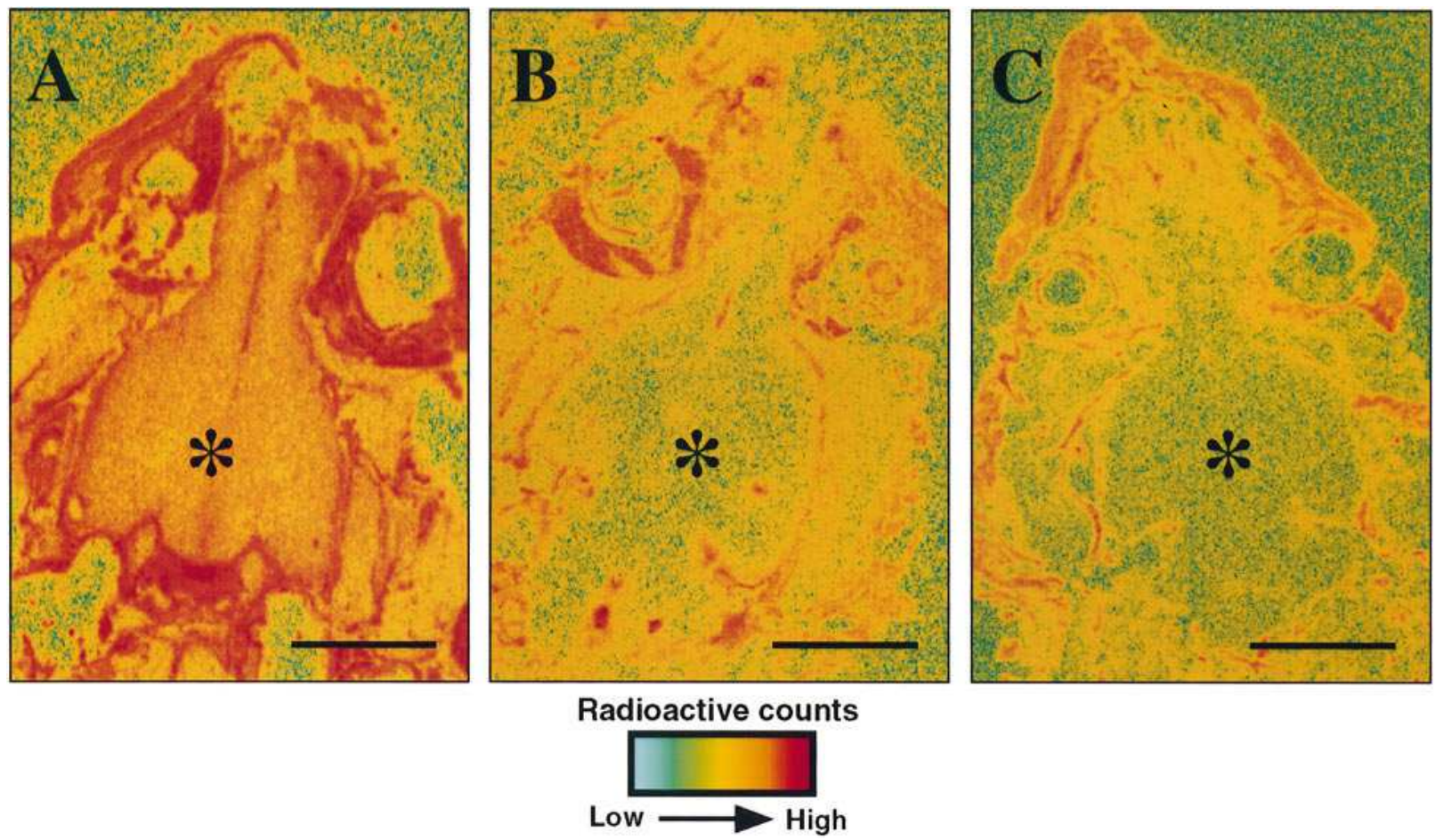

Figure 2. Brain digital autoradiography of rat with ${ }^{14} \mathrm{C}$-labeled ascorbic acid, dehydroascorbic acid, and sucrose. $(A)$ Digital autoradiography was performed on a Fischer F344 rat (8 wk of age) 3 min after intravenous injection with $40 \mu \mathrm{Ci}$ of $\left[{ }^{14} \mathrm{C}\right]$ dehydroascorbic acid, $(B) 40 \mu \mathrm{Ci}$ $\left[{ }^{14} \mathrm{C}\right]$ ascorbic acid, and $(C) 40 \mu \mathrm{Ci}\left[{ }^{14} \mathrm{C}\right]$ sucrose ([glucose- $\left.{ }^{14} \mathrm{C}(\mathrm{U})\right]$-sucrose, specific activity, $310 \mathrm{mCi} / \mathrm{mmol}$, DuPont-NEN). *Represents the area of the brain. Scale bars $=1 \mathrm{~cm}$. 
Inhibition of blood-brain barrier vitamin $C$ transport by $D$-deoxyglucose. GLUT1 is expressed on endothelial cells at the blood-brain barrier, and is responsible for glucose transport into the brain $(32,33)$. The glucose transporter GLUT1 selectively transports D-glucose, but not L-glucose. To confirm that dehydroascorbic acid passed the blood-brain barrier through GLUTs, we determined the ability of D- and L-glucose to inhibit vitamin $\mathrm{C}$ uptake. A mouse has a baseline blood glucose concentration of $\sim 5-7 \mathrm{mM}$ or $2.67 \mathrm{mg}$ glucose in the entire mouse, based on an average blood volume. The amount of exogenous glucose administered in this experiment was based on whole mouse blood glucose and subsequent multiples to a maximum tolerable amount. The concentrations of both blood glucose and dehydroascorbic acid in the mice change rapidly and widely during the time after injection, and therefore it was difficult to obtain meaningful data. 2-Deoxy-D-glucose (D-deoxyglucose) and D-glucose (data not shown) inhibited up to $70 \%$ of dehydroascorbic acid uptake in the brain in a dose-dependent fashion, whereas L-glucose and leucine had no effect (Fig. $3 A$ ). The uptake of leucine, which is not transported by GLUTs, but crosses the blood-brain barrier largely through L system transporters, and to a minor extent by the ASC system transporter (34), was not affected by increasing concentrations of L-glucose or D-deoxyglucose (Fig. $3 \mathrm{~B}$ ), nor were the serum concentrations of ascorbic acid, dehydroascorbic acid, and leucine affected by increasing concentrations of D-deoxyglucose or L-glucose (data not shown). These results establish that D-deoxyglucose inhibits dehydroascorbic acid from entering the brain through the glucose transporters, but does not affect certain other transport systems or alter general blood-brain barrier permeability by osmotic effects.

Calculation of the blood-brain barrier permeability-surface area product. The external organ approach, using serum as the

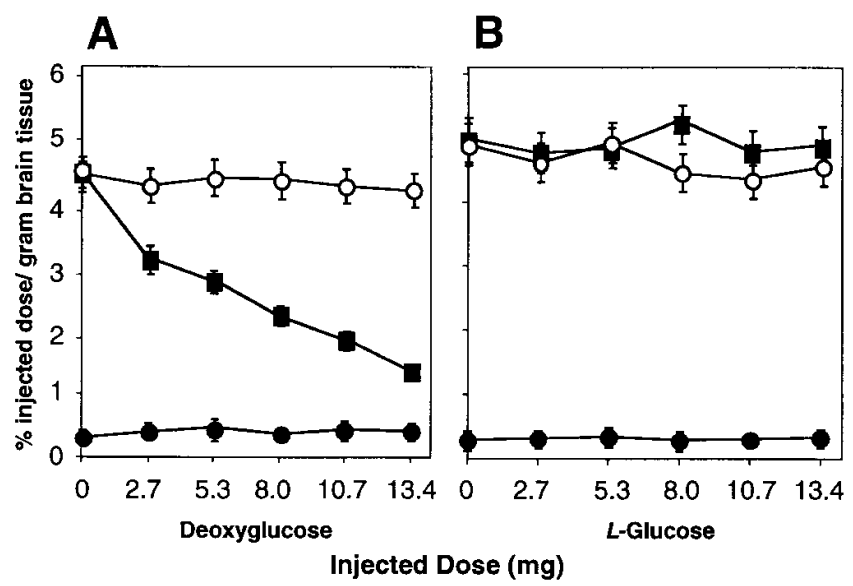

Figure 3. Specificity of the transport of dehydroascorbic acid through GLUT1 at the mouse blood-brain barrier. $(A)\left[{ }^{14} \mathrm{C}\right]$ Dehydroascorbic acid ( $\square)$ entered the brain, and its accumulation was blocked by increasing amounts of D-deoxyglucose that is transported through GLUT1. Transport of $\left[{ }^{3} \mathrm{H}\right]$ leucine $(\bigcirc)$ or $\left[{ }^{14} \mathrm{C}\right]$ ascorbic acid $(\bullet)$ across the blood-brain barrier was not affected by D-deoxyglucose. $(B)$ L-glucose, which is not transported through GLUT1, had no effect on the transport of $\left[{ }^{14} \mathrm{C}\right]$ dehydroascorbic acid. Transport of $\left[{ }^{3} \mathrm{H}\right]$ leucine $(\mathrm{O})$ or $\left[{ }^{14} \mathrm{C}\right]$ ascorbic acid $(\bullet)$ across the blood-brain barrier was not affected by L-glucose. All experiments were carried out over a 30-s time course. Each data set included four mice, and the data were expressed as mean \pm SEM. external organ, was used to calculate the blood-brain barrier permeability-surface area product (PS) in the Fischer F344 rat (35). The calculated PS of $\left[{ }^{14} \mathrm{C}\right]$ dehydroascorbic acid was $136 \pm 12(\mathrm{SEM}) \mu \mathrm{l} / \mathrm{min} / \mathrm{g}$ brain tissue, that of $\left[{ }^{14} \mathrm{C}\right]$ ascorbic acid was $-0.44 \pm 0.24 \mu \mathrm{l} / \mathrm{min} / \mathrm{g}$ brain tissue, and that of [ $\left.{ }^{3} \mathrm{H}\right]-\mathrm{D}-d e o x y-$ glucose was $44 \pm 3.2 \mu \mathrm{l} / \mathrm{min} / \mathrm{g}$ brain tissue. The difference in the blood-brain barrier PS between ascorbic acid and dehydroascorbic acid illustrated the marked differences in the blood-brain barrier transport between the redox states of vitamin C. The calculated PS of ascorbic acid was $\sim 0 \mu \mathrm{l} / \mathrm{min} / \mathrm{g}$ brain tissue at $30 \mathrm{~s}$, similar to that of sucrose, which indicates no transport across the blood-brain barrier.

\section{Discussion}

The results of this study established that the transport of vitamin $\mathrm{C}$ into the brain is mediated by glucose transporters at the blood-brain barrier that transport dehydroascorbic acid. We found no measurable transport of ascorbic acid across the blood-brain barrier at short time intervals. It is possible that the blood-brain barrier has a means to transport ascorbic acid slowly since a small amount of brain uptake was seen $30 \mathrm{~min}$ after ascorbic acid injection. Transport of ascorbic acid may be underestimated in our study because of competition of the radiolabeled ascorbic acid by ascorbic acid in the blood. The calculated concentration of radiolabeled ascorbic acid in the mouse studies, however, was $\sim 250 \mu \mathrm{M}$, which is 2.5 to 3 times the blood concentration of ascorbic acid in the mouse (37). Thus, from a simple kinetic analysis, we calculate no more than a maximum of $30 \%$ potential competition of transport of the radiolabeled material. Similarly, endogenous glucose is expected to compete partially for dehydroascorbic acid uptake across the blood-brain barrier in our assays, although to a minor extent. The blood concentration of glucose in normal rodents is $\sim 5-7 \mathrm{mM}$, yet dehydroascorbic acid was readily transported into the brain across the blood-brain barrier. Both dehydroascorbic acid and glucose are substrates of the glucose transporters under physiologic conditions. Our results are consistent with in vitro data demonstrating that a deoxyglucose concentration $>50 \mathrm{mM}$ is necesary to block the transport of dehydroascorbic acid through GLUT1 $(17,18)$. The kinetic constant $\left(K_{\mathrm{m}}\right)$ of the blood-brain barrier transport of glucose is $11.0 \pm 1.4 \mathrm{mM}$ (38). Thus, a blood glucose concentration of $\sim 11 \mathrm{mM}$ would be necessary to block $50 \%$ of the transport of dehydroascorbic acid. Our in vivo experiments show that a severalfold increase in blood glucose caused a dose-dependent inhibition of dehydroascorbic acid accumulation in the brain. We were unable to completely inhibit dehydroascorbic acid transport in the brain in these experiments because we were not able to increase blood glucose concentration above 25-30 mM.

The permeability-surface area product of dehydroascorbic acid was threefold greater than that of D-deoxyglucose, which agrees with the difference in the $K_{\mathrm{m}}$ values between the two compounds. The apparent $K_{\mathrm{m}}$ of D-deoxyglucose for transport was $2.5 \mathrm{mM}$ in HL-60 cells, compared with an apparent $K_{\mathrm{m}}$ of $0.85 \mathrm{mM}$ for dehydroascorbic acid in HL-60 cells (17, 18). The glucose transporter at the blood-brain barrier was found to function in vivo comparably to in vitro models of the facilitative hexose transporters in that only the oxidized form of vitamin $\mathrm{C}$, dehydroascorbic acid, was transportable (16-18). GLUT1, an isoform of the glucose transporter, is ex- 


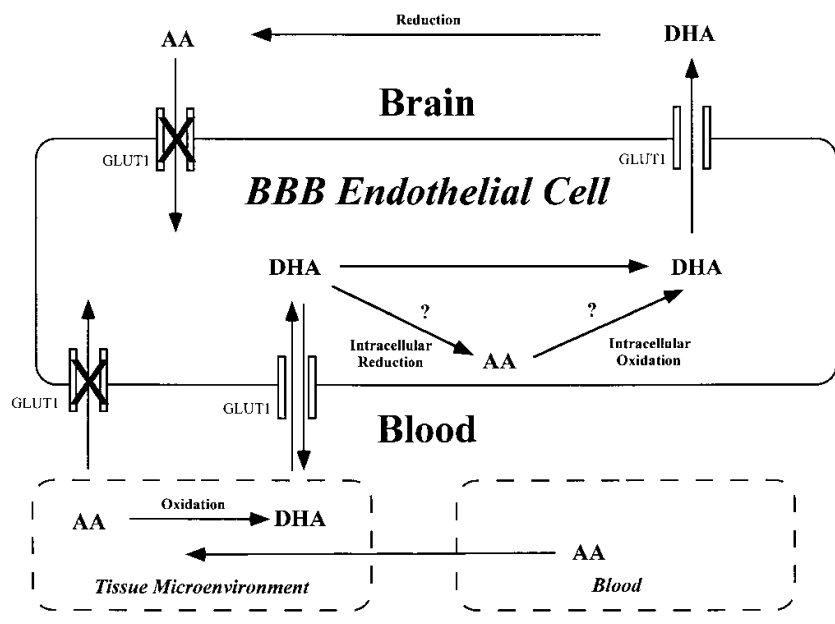

Figure 4. A proposed mechanism of vitamin $\mathrm{C}$ transport and accumulation in the brain. AA, the predominant form of vitamin $\mathrm{C}$ in blood, is oxidized to dehydroascorbic acid DHA in the tissue microenvironment. Oxidation is thus a regulatory step for brain transport of vita$\min$ C. The DHA is then transported through GLUT1 at the surface of the blood-brain barrier endothelial cell. The DHA is transported out of the endothelial cell through GLUT1. DHA may first be reduced to AA inside the cell, and then be oxidized for export through GLUT1, although there are little data concerning this step. The DHA in the brain is then reduced to AA, which is trapped in the brain because it cannot be transported through GLUT1 (36).

pressed at the blood-brain barrier on endothelial cells, and was responsible for the dehydroascorbic acid transport. Dehydroascorbic acid was reduced to ascorbic acid after passing the blood-brain barrier, and was retained in the brain as ascorbic acid. This trapping mechanism allows for accumulation of substantially higher concentrations of vitamin $\mathrm{C}$ in the brain than in the blood. A model for vitamin $\mathrm{C}$ accumulation in the brain is summarized in Fig. 4.

The current recommended daily allowance of vitamin $\mathrm{C}$ is $60 \mathrm{mg}$, and yields a steady-state plasma concentration of $\sim 24 \mu \mathrm{M}$ in human volunteers (39). The vitamin $\mathrm{C}$ detected in the serum is in the form of ascorbic acid, with dehydroascorbic acid at trace or unmeasurable serum levels (27). Thus, vitamin $\mathrm{C}$ exists in the blood as ascorbic acid, and must be converted to dehydroascorbic acid in order to traverse the blood-brain barrier through the glucose transporter. Therefore, our results point to oxidation of ascorbic acid as a potentially important step in regulating vitamin $\mathrm{C}$ entry into the brain. The mechanism and location of in vivo vitamin $\mathrm{C}$ oxidation is not known.

James Lind detailed the clinical description of scurvy in $A$ Treatise of the Scurvy in 1772 . He concluded his report of the autopsy results of scorbutic patients' "ravaged bodies" as follows: "What was very surprising, the brains of those poor creatures were always sound and entire ..." (40). Therefore, there appeared to be a mechanism for accumulation and storage of ascorbic acid in the brain such that the brain would be the last organ depleted of vitamin $\mathrm{C}$. The normal human brain has a vitamin $\mathrm{C}$ concentration of $\sim 1 \mathrm{mM}, 10$ times the normal serum concentration (37). The precise role of vitamin $\mathrm{C}$ in the brain is uncertain, but ascorbic acid may be a cofactor of dopamine $\beta$-hydroxylase, and thus involved in the biosynthesis of catecholamines. Vitamin $\mathrm{C}$ can also inhibit the peroxidation of membrane phospholipids and act as a scavenger of free radicals in the brain $(7,8)$. Our findings in this study suggest that vitamin $\mathrm{C}$ concentrations in the brain could be increased by increasing the blood concentration of dehydroascorbic acid. Dehydroascorbic acid is trapped in the brain and in cells by reduction to ascorbic acid. The mechanism of dehydroascorbic acid reduction is not known, but it is believed to be related to glutathione and/or glutathione-dependent reductases (41-43). In HL-60 myeloid leukemia cells, glutathione or glutathione-dependent reductases are not needed for dehydroascorbic acid reduction (44). There is also evidence for the existence of a glutathione-independent, NADPH-dependent mechanism to reduce dehydroascorbic acid in rat liver (45). Dehydroascorbic acid reduction requires electron donation, and the mechanism of donor regeneration is not known. It is possible that a large amount of dehydroascorbic acid in the brain may overwhelm the brain's reductive capacity, but there is no evidence to this point.

Our results define a mechanism by which the brain obtains and retains vitamin $\mathrm{C}$. We demonstrate that vitamin $\mathrm{C}$ enters the brain in the form of dehydroascorbic acid through GLUT1 at the blood-brain barrier, and is reduced and retained in the brain as ascorbic acid. These results have implications for increasing antioxidant potential in the central nervous system.

\section{Acknowledgments}

We thank Young-Mee Yi and Parag Shah for technical assistance, and E. Koers for editorial assistance.

This work was supported by National Institutes of Health grants R01CA30388, R01HL42107, P30CA08748 (D.B. Agus, D.W. Golde, and J.C. Vera) and NS25554 (W.M. Pardridge). D.B. Agus is supported by a Physician's Research Training Award from the American Cancer Society.

\section{References}

1. Chatterjee, I.B., A.K. Majumder, B.K. Nandi, and N. Subramanian. 1975. Synthesis and some major functions of vitamin $\mathrm{C}$ in animals. Ann. NY Acad. Sci. 258:24-47.

2. Rose, R.C., J.L. Choi, and M.J. Koch. 1988. Intestinal transport and metabolism of oxidized ascorbic acid. Am. J. Physiol. 254:G824-G828.

3. Spector, R., and A.V. Lorenzo. 1973. Ascorbic acid homeostasis in the central nervous system. Am. J. Physiol. 225:757-763.

4. Spector, R. Vitamin homeostasis in the central nervous system. 1977. $N$. Engl. J. Med. 296:1393-1398.

5. Crandon, J.H., C.C. Lund, and D.B. Dill. 1940. Experimental human scurvy. N. Engl. J. Med. 223:353-369.

6. Hodges, R.E., J. Hood, J.E. Canham, H.E. Sauberlich, and E.M. Baker 1971. Clinical manifestations of ascorbic acid deficiency in man. Am. J. Clin. Nutr. 24:432-443.

7. Englard, S., and S. Seifter. 1986. The biochemical functions of ascorbic acid. Ann. Rev. Nutr. 6:365-406.

8. Padh, H. 1990. Cellular functions of ascorbic acid. Biochem. Cell Biol. 68 : 1166-1173.

9. Kaufman, S. 1966. Coenzymes and hydroxylases: ascorbate and dopamine-beta-hydroxylase; tetrahydropteridines and phenylalanine and tyrosine hydroxylases. Pharmacol. Rev. 18:61-69.

10. Schreiber, M., and S. Trojan. 1991. Ascorbic acid in the brain. Physiol. Res. 40:413-418.

11. Ehrlich, P. 1885. Das Sauerstoff-Bedurfnis des Organismus: eine Farbenanalytische Studie. Hirschwald, Berlin.

12. Ehrlich, P. 1902. Uber beziehunger von chemischer constitution, vertheilung, und pharmakologischer wirlung. In Collected Studies in Immunity. John Wiley \& Sons, Inc. New York. 567-595.

13. Reese, T.S., and M.J. Karnovsky. 1967. Fine structural localization of a blood-brain barrier to exogenous peroxidase. J. Cell Biol. 34:207-217.

14. Brightman, M.W. 1977. Morphology of blood-brain interfaces. Exp. Eye Res. 25 (Suppl.):1-25.

15. Pardridge, W.M. 1983. Brain metabolism: a perspective from the bloodbrain barrier. Physiol. Rev. 63:1481-1535. 
16. Vera, J.C., C.I. Rivas, J. Fischbarg, and D.W. Golde. 1993. Mammalian facilitative hexose transporters mediate the transport of dehydroascorbic acid. Nature. 364:79-82.

17. Vera, J.C., C.I. Rivas, R.H. Zhang, C.M. Farber, and D.W. Golde. 1994. Human HL-60 myeloid leukemia cells transport dehydroascorbic acid via the glucose transporters and accumulate reduced ascorbic acid. Blood. 84:16281634.

18. Vera, J.C., C.I. Rivas, F.V. Velasquez, R.H. Zhang, I.I. Concha, and D.W. Golde. 1995. Resolution of the facilitated transport of dehydroascorbic acid from its intracellular accumulation as ascorbic acid. J. Biol. Chem. 270: 23706-23712.

19. Siliprandi, L., P. Vanni, M. Kessler, and G. Semenza. 1979. $\mathrm{Na}^{+}$-dependent, electroneutral L-ascorbate transport across brush border membrane vesicles from guinea pig small intestine. Biochim. Biophys. Acta. 552:129-142.

20. Patterson, L.T., D.L. Nahrwold, and R.C. Rose. 1982. Ascorbic acid uptake in guinea pig intestinal mucosa. Life Sci. 31(24):2783-2791.

21. Diliberto, E., Jr., G.D. Heckman, and A.J. Daniels. 1983. Characterization of ascorbic acid transport by adrenomedullary chromaffin cells. Evidence for $\mathrm{Na}^{+}$-dependent co-transport. J. Biol. Chem. 258:12886-12894.

22. Padh, H., and J.J. Aleo. 1987. Characterization of the ascorbic acid transport by 3T6 fibroblasts. Biochim. Biophys. Acta. 901(2):283-290.

23. DiMattio, J. 1989. Active transport of ascorbic acid into lens epithelium of the rat. Exp. Eye Res. 49(5):873-885.

24. Helbig, H., C. Korbmacher, J. Wohlfarth, S. Berweck, D. Kuhner, and M. Wiederholt. 1989. Electrogenic $\mathrm{Na}^{+}$-ascorbate cotransport in cultured bovine pigmented ciliary epithelial cells. Am. J. Physiol. 256(1 Pt. 1):C44-C49.

25. Wilson, J.X., and S.J. Dixon. 1989. High-affinity sodium-dependent uptake of ascorbic acid by rat osteoblasts. J. Membr. Biol. 111(1):83-91.

26. Dyer, D.L., Y. Kanai, M.A. Hediger, S.A. Rubin, and H.M. Said. 1994. Expression of a rabbit renal ascorbic acid transporter in Xenopus laevis oocytes. Am. J. Physiol. 267(1 Pt. 1):C301-C306.

27. Dhariwal, K.R., W.O. Hartzell, and M. Levine. 1991. Ascorbic acid and dehydroascorbic acid measurements in human plasma and serum. Am. J. Clin. Nutr. 54:712-716.

28. Abdel el Motal, S.M., and G.W. Sharp. 1985. Inhibition of glucoseinduced insulin release by xylazine. Endocrinology. 116:2337-2340.

29. Hsu, W.H., and S.K. Hummel. 1981. Xylazine-induced hyperglycemia in cattle: a possible involvement of alpha 2-adrenergic receptors regulating insulin release. Endocrinology. 109:825-829.

30. Kawamoto, T., and M. Shimizu. 1986. A method for preparing wholebody sections suitable for autoradiographic, histological and histochemical studies. Stain Technol. 61:169-183.

31. Triguero D., J. Buciak, and W.M. Pardridge. 1990. Capillary depletion method for quantification of blood-brain barrier transport of circulating peptides and plasma proteins. J. Neurochem. 54:1882-1888.

32. Crone, C. 1965 . Facilitated transfer of glucose from blood into brain tissue. J. Physiol. 181:103-113.

33. Pardridge, W.M., R.J. Boado, and C.R. Farrell. 1990. Brain-type glucose transporter (GLUT-1) is selectively localized to the blood-brain barrier. Studies with quantitative western blotting and in situ hybridization. J. Biol. Chem. 265:18035-18040.

34. Cangiano, C., P. Cardelli-Cangiano, J.H. James, F. Rossi-Fanelli, M.A. Patrizi, K.A. Brackett, R. Strom, and J.E. Fischer. 1983. Brain microvessels take up large neutral amino acids in exchange for glutamine. Cooperative role of $\mathrm{Na}^{+}$-dependent and $\mathrm{Na}^{+}$-independent systems. J. Biol. Chem. 258:8949-8954.

35. van Uitert, R.L., J.I. Sage, D.E. Levy, and T.E. Duffy. 1981. Comparison of radio-labeled butanol and iodoantipyrine as cerebral blood flow markers. Brain Res. 222:365-372.

36. Rose, R.C. 1993. Cerebral metabolism of oxidized ascorbate. Brain Res. 628:49-55.

37. Hornig, D. 1975. Distribution of ascorbic acid, metabolites and analogues in man and animals. Ann. NY Acad. Sci. 258:103-118.

38. Pardridge, W.M., and W.H. Oldendorf. 1975. Kinetics of blood-brain barrier transport of hexoses. Biochim. Biophys. Acta. 382:377-392.

39. Levine, M., C. Conry-Cantilena, Y. Wang, R.W. Welch, P.W. Washko, K.R. Dhariwal, J.B. Park, A. Lazarev, J.F. Graumlich, J. King, and L.R. Cantilena. 1996. Vitamin C pharmacokinetics in healthy volunteers: evidence for a recommended dietary allowance. Proc. Natl. Acad. Sci. USA. 93:3704-3709.

40. Stewart, C.P., and D. Guthrie. 1953. Lind's Treatise on Scurvy. Edinburgh University Press, Edinburgh. 227-231.

41. Wells, W.W., D.P. Xu, Y. Yang, and P.A. Rocque. 1990. Mammalian thioltransferase (glutaredoxin) and protein disulfide isomerase have dehydroascorbate reductase activity. J. Biol. Chem. 265:15361-15364.

42. Winkler, B.S. 1992. Unequivocal evidence in support of the nonenzymatic redox coupling between glutathione/glutathione disulfide and ascorbic acid/dehydroascorbic acid. Biochim. Biophys. Acta. 1117:287-290.

43. Bode, A.M., E. Green, C.R. Yavarow, S.L. Wheeldon, S. Bolken, Y. Gomez, and R.C. Rose. 1993. Ascorbic acid regeneration by bovine iris-ciliary body. Curr. Eye Res. 12:593-601.

44. Guaiquil, V.H., C.M. Farber, D.W. Golde, and J.C. Vera. 1997. Efficient transport and accumulation of vitamin C in HL-60 cells depleted of glutathione. J. Biol. Chem. 272:9915-9921.

45. May, J.M., S. Mendiratta, K.E. Hill, and R.F. Burk. 1997. Reduction of dehydroascorbate to ascorbate by the selenoenzyme thioredoxin reductase. $J$. Biol. Chem. 272:22607-22610. 